\title{
Current Status of the Campus Football Activities in the Primary Schools of Qingdao City and the Countermeasure Research
}

\author{
Zhenbo SUN \\ Qingdao Binhai University \\ College of Liberal Arts Foundation \\ Qingdao, Shandong, 266555
}

\author{
Qianxia SUI \\ Qingdao Binhai University \\ College of Arts and Communications \\ Qingdao, Shandong, 266555
}

\begin{abstract}
In order to better promote the implementation of Chinese teenagers' campus football, this paper takes Qingdao City, one of the first batch of national-level campus football promotion and distribution cities as an example, conducts field investigation and analysis about the implementation conditions of campus football activities in primary schools of Qingdao Municipal Jurisdiction, then explores the factors influencing the implementation of football activities in primary schools of Qingdao City, finally solves the problem. Meanwhile, it has also put forward targeted suggestions for the further implementation of campus football activities in the primary schools of Qingdao City to better promote the implementation of campus football activities in primary schools of Qingdao City.
\end{abstract}

Keywords-Football sports; Campus football; Current status about the implementation; Countermeasures research

\section{INTRODUCTION}

Football policies have been frequently released from top to bottom, which has indicated the determination of all levels of government to promote the football of our country. Football sports are the same with other sports, and only when teenagers are seized can we seize the future of football. As time requires, the important approach is to regard campus as the breakthrough for football, and regard campus football as the foundation for realizing football popularity, expanding football population scale, tamping football talents, and developing football career. However, due to the implementation of policies, the formulation and implementation of measures as well as the existence of objective conditions, etc., it is inevitably to cause certain influence on the implementation of campus football. Through investigating the current status about the implementation of campus football in 20 primary schools of Qingdao City, it has conducted current status analysis from four aspects, including the facility status in the football field of primary schools in Qingdao City, the current status about PE teachers in primary schools of Qingdao City, the attitude of primary school student parents towards the students' participation in football campus in Qingdao City, and the attitude of campus managers towards the implementation of campus football in Qingdao City, and then found out the factors influencing the implementation of campus football activities in primary schools of Qingdao City and put forward targeted suggestions and strategies.

\section{CURRENT STATUS OF THE CAMPUS FOOTBALL} ACTIVITIES IN THE PRIMARY SCHOOLS OF QINGDAO CITY AND THE ANALYSIS OF INFLUENCING FACTORS

Regard the current status about the implementation of campus football in 20 primary schools of Qingdao City as the research object, including 12 urban primary schools, 4 urban and rural primary schools, and 4 rural primary schools.

A. The ratio of football facilities is unbalanced in urban and rural primary schools, and football characteristic schools have outstanding hardware and software

The sports field devices of a school are the basic guarantee for carrying out the sports activity in the school, and is also the basic condition to test the comprehensive strength of a school [1]. Football field is the most basic facility to carry out football sports. Along with the popularization of campus football, more and more people will participate, which will cause more and more demands for fields and devices. The occupied area of the field per capita and the quantity of equipment are also the standard requested for measuring whether the field devices of a school can meet the implementation of campus football activities. As one of the first batch of campus football pilots, and also one of the economically developed coastal cities, Qingdao has gained high attentions from the government in education investment. All the primary schools in Qingdao City have the football field required for carrying out football activities, but the hardware supporting facilities in each school are of varying quality; please refer to Table 1 for the investigation result.

CLC No.: G843 Document code: A 
TABLE I.

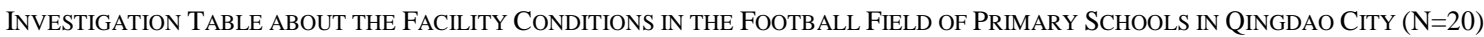

\begin{tabular}{|l|c|c|}
\hline Options & Quantity of schools & Proportion (\%) \\
\hline Standard football field & 5 & 25 \\
\hline Small-scaled football field & 15 & 100 \\
\hline Football & 20 & 70 \\
\hline Football door & 14 & 60 \\
\hline Soft ladder for football training & 12 & 80 \\
\hline Mark barrel & 16 & 100 \\
\hline Barrier bar & 20 & 50 \\
\hline Jump ladder & 10 & 50 \\
\hline Agile circle & 10 & 50 \\
\hline
\end{tabular}

Through the school investigation, it has been found that the football, football door, barrier bar, mark barrel and other devices used for courses and training are relatively sufficient, especially footballs; each class can averagely have 2-3 footballs, and can meet the use for courses and the training. The soft ladder, jump ladder, agile circle and other devices related to football training should be further perfected. There are only 5 schools possessing standard field, and can occupy $25 \%$, but all of these schools are football characteristic schools, while these fields are basically focused on artificial turf. organizers and guiders of campus football activities, and they not only need to bear the teaching task of PE courses, but also act as the football coaches, competition judges and other work. This has put forward an extremely high requirement for their comprehensive quality. The academic qualification conditions about the PE teachers in primary schools of Qingdao City are as shown in Table 2. On the whole, the academic qualification structure is moderate for PE teachers in primary schools of Qingdao City, while the academic qualification layer is lower for PE teachers in urban and rural primary schools.

\section{B. The lack of professional football teachers has become the bottleneck that restricts the football development of primary schools}

$\mathrm{PE}$ is one of the two courses, and it is an important component of education in the school. PE teachers are also the

TABLE II. List of PE Teachers' ACAdemic Qualification IN Primary Schools of Qingdao City (N=40)

\begin{tabular}{lcccccc}
\hline Level & $\begin{array}{c}\text { Doctoral } \\
\text { candidates }\end{array}$ & $\begin{array}{c}\text { Postgraduate } \\
\text { students }\end{array}$ & Undergraduate & $\begin{array}{c}\text { Junior } \\
\text { College }\end{array}$ & $\begin{array}{c}\text { Technical } \\
\text { Secondary } \\
\text { School }\end{array}$ & $\begin{array}{c}\text { Retired } \\
\text { athletes }\end{array}$ \\
\hline $\begin{array}{l}\text { Tuantity } \\
\text { Proportion }\end{array}$ & 0 & 10 & 21 & 4 & 2 & 3 \\
$(\%)$
\end{tabular}

The age conditions about the PE teachers in primary schools of Qingdao City are as shown in Table 4. As can be

seen from the investigation result, the age for PE teachers in primary schools of Qingdao City has a younger tendency.

TABLE III. List of PE Teachers' Age IN Primary Schools of Qingdao City (N=40)

\begin{tabular}{ccccccc}
\hline Age & Under 30 years old & 30-40 years old & 40-50 years old & Over 50 years old & Total \\
\hline Quantity & 15 & 13 & 8 & 4 & 40 \\
Proportion $(\%)$ & 37.5 & 32.5 & 20 & 10 & 100 \\
\hline
\end{tabular}

Primary schools are the key component for cultivating coaches is the key factor influencing the quality of football football backup talents, and the professional quality of football backup talents. Along with the popularization and promotion of 
campus football, the problems of few football coaches and low level have been highlighted. Some schools have few football coaches, while some schools don't have any professional football coaches. In order to meet the demands for carrying out campus football activities, some schools' PE teachers start to change profession and learn football, and then start to teach football after participating in several training classes, and due to bad foundation and unscientific training method, this has caused such teaching while learning approach has restricted the implementation of campus football sports [2].

\section{The attitude of parents towards the students' participation in campus football will influence the participation degree of campus football.}

Since the participation subjects for campus football activities are students, due to small age, their selections for many things are based on the guidance of their parents, and most children should obtain the consent of parents to participate in sports activities. Thus, family factor plays an important role in campus football activities, and parents are the decisive factor considering whether children can participate in football activities, and their attitudes will influence the participation base number of campus football activities.

TABLE IV. List OF PARENTs' AtTITUde TOWARDS THE CHILDREN'S PARTICIPATION IN CAMPUS FoOTBALl ACTIVITIES IN PRIMARY SCHOOLS OF QINGDAO CITY $(\mathrm{N}=91)$

\begin{tabular}{lcccccc}
\hline Parents' attitude & $\begin{array}{c}\text { Strongly } \\
\text { support }\end{array}$ & $\begin{array}{c}\text { Relatively } \\
\text { support }\end{array}$ & Support & Not support & $\begin{array}{c}\text { Strongly not } \\
\text { support }\end{array}$ & Total \\
\hline Quantity & 30 & 21 & 16 & 18 & 6 & 91 \\
Proportion $(\%)$ & 32.9 & 23.1 & 17.6 & 19.8 & 6.6 & 100 \\
\hline
\end{tabular}

Through the interview, we know that most parents have the initial understanding about campus football sports through the network, TV and other channels, and most parents support their own children to participate in campus football activities. As can be seen from the investigation of Table 4: The total quantity of parents who strongly support, relatively support and support them to participate in campus football activities can occupy $73.6 \%$, and such proportion is also relatively high, but there are also $26.4 \%$ parents don't support their children to participate in campus football activities. The part of parents who doesn't hold support attitude mainly worries that playing football will influence their children's academic record, especially the parents of students in Grade 5 and Grade 6. Children are about to enter junior high school with big study pressure; Secondly, football itself is a sport with physical confrontation, and this will inevitably generate some injuries, so some parents worry about the safety of their children and don't support them to participate in campus football sports;

they would like them to participate in some sports activities with no physical confrontation; Thirdly, some parents think that Chinese football is the most futureless sports, and the reason is that they cannot see any hope in Chinese football, and this concept has exactly violated the development concept of "starting with young kids for football".

\section{The leading effect exerted by the campus managers of Qingdao City on the implementation of campus football}

The vigorous implementation of certain activity cannot be separated from the big support and the attentions of leaders, while necessary teacher reservation, fund input and time arrangement are the important precondition and material foundation considering whether campus football can be validly implemented, so the conditions about the implementation conditions of campus football in various primary schools depend on the attitude of the leaders to a great extent [3].

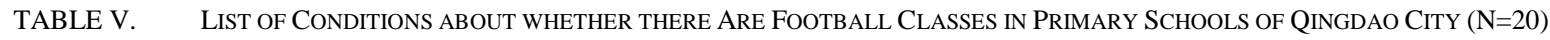

\begin{tabular}{lccc}
\hline $\begin{array}{l}\text { Whether there are football } \\
\text { classes }\end{array}$ & There are football classes & $\begin{array}{c}\text { There are no football } \\
\text { classes }\end{array}$ & Total \\
\hline
\end{tabular}

Quantity of schools 20

Proportion $(\%)$
100
0

0
20

100

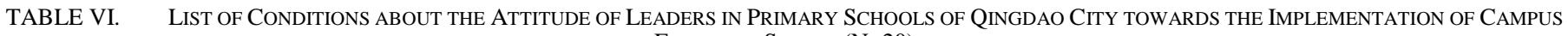
FOOTBALL SPORTS $(\mathrm{N}=20)$

\begin{tabular}{|c|c|c|c|c|c|c|}
\hline Leaders' attitude & $\begin{array}{c}\text { Strongly } \\
\text { support }\end{array}$ & $\begin{array}{l}\text { Relatively } \\
\text { support }\end{array}$ & Support & Not support & $\begin{array}{l}\text { Strongly not } \\
\text { support }\end{array}$ & Total \\
\hline Quantity & 9 & 7 & 4 & 0 & 0 & 20 \\
\hline Proportion (\%) & 45 & 35 & 20 & 0 & 0 & 100 \\
\hline $\begin{array}{l}\text { On February } 27 \text {, } \\
\text { nprehensively dee } \\
\text { roved the Overall } \\
\text { in the Scheme, it } \mathrm{h}\end{array}$ & $\begin{array}{l}\text { the ce } \\
\text { the ref } \\
\text { for Foc } \\
\text { ly put for }\end{array}$ & $\begin{array}{l}\text { overnment } \\
\text { oup and } \\
\text { eform in Ch } \\
\text { include foot }\end{array}$ & $\begin{array}{l}\text { Thus, th } \\
\text { Qingdao } \\
\text { activities }\end{array}$ & $\begin{array}{l}\text { itudes of the } \\
\text { towards the } \\
\text { e elevated to }\end{array}$ & $\begin{array}{l}\text { iders of the } p \\
\text { olementation } \\
\text { ew height. As }\end{array}$ & $\begin{array}{l}\text { iry sch } \\
\text { mpus } \\
\text { be see }\end{array}$ \\
\hline
\end{tabular}


the investigation result in Table 5, the proportion of primary schools in Qingdao City to include football into the classroom is $100 \%$. According to the investigation result in Table 6: The campus football sports have obtained $100 \%$ support from school leaders.

The attitude of school leaders will influence the implementation of a sport, and will implement it, if they like it, vice versa. The implementation of campus football activities in primary schools of Qingdao City has gained general support from school leaders, but the support doesn't mean that it can be well implemented. In the face of policies, some schools merely work for appearance sake, shout slogans, and will only do it, in case of any inspection. The comprehensive evaluation of the society for a school ultimately depends on the teaching quality of a school, while school-level leaders will firstly consider the ratio of all aspects of resources and firstly apply them in teaching, and then consider the implementation of other work. The profits brought to the school for winning a teaching competition award are higher than the profits for winning football competition awards. In order to carry out a better football characteristic school, the first thing is to obtain big support from school-level leaders considering the building, training, and competition of football teams, and then it is requested to firstly emphasize on building the sports team and then radiate to the football sports of the entire school as per the mode of point-to-area, and then further improve the overall level of campus football sports.

\section{COUNTERMEASURES FOR CARRYING OUT FOOTBALL ACTIVITIES IN PRIMARY SCHOOLS OF QINGDAO CITY}

\section{A. Build campus football culture, and arouse students' participation enthusiasm}

Implement "health first" spirits, cultivate "happy football" campus football concept and build a good campus football culture. (1) Periodically hold campus football culture festival, and publicize the campus football sports; (2) Adopt football competition mode to carry out campus football theme month activity; (3) Conduct campus football baby audition and other artistic and cultural activities; (4) Energetically promote "One Yuan for watching China League One" activity brand. Through these activities, make more and more students have an in-depth understanding about football, and then make them love football, and make football become a component of students' study life, and root in the campus. Meanwhile, it is also requested to reinforce the publicity of campus football cultivation function.

\section{B. Build safety assurance mechanism, and eliminate the doubts of parents}

Safety is the permanent topic of sports work in the school, and also the concerns of parents about the participation of students in campus football; the following six suggestions for the safety assurance mechanism are put forward specific to the investigation result: (1) Implement the safety responsibility mechanism step by step, reinforce the safety education of students and make them master the methods of self-protection and self-rescue. (2) Build and perfect the hygiene mechanism for campus football activity, establish campus football activity injury treatment group and formulate feasible treatment schemes. (3) PE teachers should improve work responsibility, and should carefully check the field, and devices before class, and then reasonably arrange the amount of exercise during the class, and conduct well pre-class preparation and post-class relax activities. (4) Students should improve their prevention awareness for campus football sports injury accidents, during exercise, it is requested to be equipped with necessary sports devices, such as wearing shin guards. (5) Specific to the sports injuries that may be incurred in the campus football activities, it is requested to positively introduce social insurance, explore and promote the additional insurance for the school's non-fault liability. When students are subject to accidents during the process of participating in sports activities and sports competition in the school or outdoor collective activities, meeting, etc., without the faults of the school, it shall bear no responsibility for civil compensation, and the compensation can be paid through the insurance company, and this can remove worries, so that campus football activities can be better implemented. (6) Reinforce the medical team construction of the school, and then as per the School Sanitation Work Regulations and the Medical Institution Management Regulations, schools should set medical room, which is equipped with experienced medical personnel or full-time (part-time) healthcare physicians, complete sanitation devices and first-aid equipment, and in case of finding any problems, adopt emergency treatment, and carry out the rescue at the first time [4]. Prevent and handle well the injury accidents that may be incurred in the implementation process of campus football sports, and ensure the legal rights and interests of students, remove the worries of students, parents and schools, so that parents are relieved to let their children participate in the campus football sports. So that the campus football sports can be vigorously developed

\section{Integrate various resources, and perfect football hardware and software facilities}

The vigorous input of the government is the valid approach to improve the football hardware conditions, and since 2016, each newly established school in Qingdao City will at least build 1 football field meeting the standards for opening to the society. This year, it will complete plastic playground for all schools in urban areas of the entire city, and conditional schools will complete the transformation from artificial turf to real turf. Realized plastic playground at all urban and rural primary schools in 2017; It has also been put forward in the Reform Implementation Schemes about the Reform Test Area of National Teenagers' Campus Football in Qingdao City that, it is requested to vigorously develop "cage football", encourage conditional schools to build roof football field, light court, etc., and the insufficient funds will be input by the public welfare fund of Chinese sports and the financial fund as per 1:1. Qingdao Municipal Sports Bureau will take the lead, and arrange 30 million public welfare funds of Chinese sports, and build 100 "cage football fields" within the entire city. These public sports fields can serve the community while being open to the surrounding schools, and football characteristic schools can preferentially use them as training fields. Try to solve the problem of small occupied area of field per capita as much as possible. Meanwhile, the construction of football field devices and other facilities cannot be separated from the support of 
social form, and through directional cooperation and other modes, social funds are introduced to improve the status of the field devices, and optimize the environment for taking classes. Integrate the resources of all aspects and promote the quality of football fields.

\section{Implement internal cultivation and external training, and improve the professional quality of football teachers}

In order to develop campus football, the key is to reinforce the equipment force for professional teachers. The state has clear regulations about the equipment of campus football teachers: National-level football characteristic school shall have at least 3 football teachers; Municipal-level football characteristic school shall have at least 2 football teachers; Other schools should have at least one football teacher [5]. There are few schools that can meet the equipment standard, and many schools have one football teacher that plays multiple roles, and the lack of professional football teachers is the real problem influencing the campus football development in primary schools of Qingdao City. As per the policies in the Implementation Schemes about the National Teenagers' Campus Football Reform Test Area in Qingdao City, introduce professional teachers through multiple channels. Firstly, actively recruit PE teachers majoring in football; Secondly, hire excellent football retired athletes as the football teacher; thirdly, introduce college football volunteers to act as the part-time football teacher. Meanwhile, it is requested to reinforce the training force for PE teachers at school, and then by virtue of the campus football teacher training platform in Qingdao City, select excellent teachers who aren't football professionals in the school, periodically conduct systematic training for them, and actively participate in football teacher training class. Encourage teachers to participate in football teaching skill competition for PE teachers in primary schools of Qingdao City, and then through these activities, improve the football skills of PE teachers and lay a solid foundation for carrying out campus football.

\section{E. Perfect the management mechanism and escort the campus football}

In the investigation, it has been found out that the current campus football management mechanism in Qingdao City is also changing, and with the changes in the campus football management subject, the campus football management subject of Qingdao City is changed to be supervised by Qingdao Municipal Education Bureau from the original Qingdao Municipal Sports Bureau. The change of campus football management subject in Qingdao City has made the responsibilities more clear, and all departments should mutually communicate and work in cooperation, and exert the function of management subject. Suggestions: (1) Perfect the campus football management mechanism, and the school should establish its own campus football management office, and the president shall act as the office director. Set campus football training\& competition office, campus football organization and publicity office, campus football field device management office, campus football expenditure management office, campus football medical insurance office, etc. All offices have a clear division of labor, and take their own responsibilities respectively, and escorted the school to better carrying out the campus football sports. (2) Perfect the campus football sports training, competition award mechanism and other regulations and rules, and award the teachers who have worked hard in the training as well as the coaches who have led in competition participation and gained achievements, and improve their training and leading enthusiasm. The perfection of regulations and rules have made all departments have rules to follow during work, and improve the work efficiency. (3) Normalize the campus football athlete and coach management methods in Qingdao City. Register each football athlete, establish personal archives for campus football athletes, coaches, and judges, and periodically arrange physical examination for them. (4) Establish professional guidance committee for campus football, hire experienced talents to guide and supervise the campus football sports, and improve the professional level of campus football. (5) Perfect the campus football competition system, and reinforce the evaluation of students' football skills. Reinforce the organic linkage between campus football competition and district league, and $U$ series of competition. Build all levels and all age groups of competition communications through multiple channels, and actively participate in higher level of competitions. Actively implement the spirits of Chinese Teenagers' and Children' s Football Training Outline, scientifically and reasonably formulate campus football evaluation standard, and regard campus football as the optional project for sports standard test [6].

\section{CONCLUSIONS}

Through referring to the "eight tasks" put forward in the national teenagers' campus football development strategic plan from the national layer, Qingdao City has made active endeavors in carrying out campus football in primary schools, and guided all the arranged schools to implement corresponding practices, and also attempted to conduct various explorations and innovations. However, it has been found out through the investigation that, under the comprehensive influence of several factors, there are still many problems in the implementation of campus football in primary schools of Qingdao City. Qingdao City should fully study the real dilemma for the campus football development in primary schools of Qingdao City, and comprehensively promote the implementation of campus football through building campus football culture, campus football safety assurance mechanism, campus football facilities, professional football teacher team, and the management mechanism, etc.

\section{ACKNOWLEDGMENT}

About the author: Zhenbo SUN (1975-), male, born in Qingdao of Shandong, Han nationality, lecturer and master; Tel.: 13864268255, Email: 727695341@qq.com 


\section{REFERENCES}

[1] Yanwang LIAO. Current Status about the Football Development in Urban Secondary Schools of Hunan Province and the Countermeasure Research [D]. Chongqing: Southwest University, 2009.

[2] Yufei GAI. Research on the Dilemma for Carrying out Campus Football in Primary and Secondary Schools in Qingdao City and the Development Route [D]. Shandong: Shandong University, 2018.

[3] Dianchen LU. Investigation Research about the Current Status for Carrying out Teenagers' Football Activities in Qingdao [D]. Shandong: Shandong Normal University, 2013.

[4] Longlong CHEN. Legal Research about the Sport Injury Accident Treatment for Students and the Prevention Mechanism for Campus Football Activity [D]. Fuzhou: Fujian Normal University, 2013.

[5] Chunmei HUANG. Research about the Validity of Implementing Campus Football Activities in Primary Schools [J]. Sports, 2018:113114.

[6] Jinping FENG. Problems in the Campus Football Development of Primary Schools and the Countermeasures [J]. Survey of Education, 2018, 7(6): 100-101 